\title{
Ultrastructural Localization of Cytochrome $b$ in the Membranes of Resting and Phagocytosing Human Granulocytes
}

\author{
A. J. Jesaitis, ${ }^{\star}$ E. S. Buescher, ${ }^{\ddagger}$ D. Harrison, ${ }^{\ddagger}$ M. T. Quinn, ${ }^{\star}$ C. A. Parkos, ${ }^{5}$ S. Livesey, ${ }^{\ddagger}$ and J. Linner \\ *Department of Chemistry, Montana State University, Bozeman, Montana 59717; \$Department of Pathology, \\ Harvard Medical School, Brigham and Women's Hospital, Boston, Massachusetts 02115; and \\ ${ }^{\ddagger}$ Cryobiological Research Center of the University of Texas, Houston, The Woodlands, Texas 77381
}

\begin{abstract}
Affinity-purified rabbit anti-neutrophil cytochrome $b$ light or heavy chain antibodies were used to immunocytochemically and biochemically localize cytochrome $b$ in neutrophils and eosinophils. The antibodies were monospecific, recognizing polypeptides of 91 and $22 \mathrm{kD}$, respectively, on Western blots of whole neutrophil extracts. The antibodies were used in Western blot analysis of subcellular fractions of purified neutrophils to confirm that the distribution of cytochrome $b$ spectral absorbance matched that of the two subunits. Thin sections of cryofixed, molecular distillation-dried granulocytes were labeled with the anti-cytochrome $b$ antibodies, followed by incubation with biotin-conjugated secondary antibody, and final labeling with streptavidin-conjugated colloidal gold. Electron microscopy revealed that the cytochrome $b$ light and heavy chains were localized primarily $(80 \%)$ to $0.1-0.2-\mu \mathrm{m}$ round or elliptical granule-like structures in neutrophils and 0.4-0.5- $\mu \mathrm{m}$ granules in eosinophils. Approximately $20 \%$ of the cytochrome $b$ was localized to the surface, confirming the subcellular fractionation studies. Double staining experiments on the neutrophils, using polyclonal rabbit anti-lactoferrin antibody, indicated that the cytochrome-bearing structures also contained lactoferrin and thus were specific granules. When the analysis was performed on neutrophils that had phagocytosed Staphylococcus aureus, cytochrome b was found in the phagosomal membrane adjoining the bacterial cell wall. ( $J$. Clin. Invest. 1990. 85:821-835.) neutrophils • polymorphonuclear leukocytes $\bullet$ superoxide generation $\bullet$ immunoelectron microscopy • cryofixation/molecular distillation drying
\end{abstract}

\section{Introduction}

The superoxide generating system $(1,2)$ of human neutrophils is essential for host defense against microbial infection $(3,4)$. The system is highly regulated and complex, consisting of a number of essential components whose genetic absence results in chronic granulomatous disease (3). One of these components, a $b$-type cytochrome has recently been purified $(5,6)$ and shown to be a heterodimeric integral membrane glycoprotein with subunits of 91 and $22 \mathrm{kD}(6 a)$. Both subunits have been cloned and sequenced $(7,8,8 a)$ and shown to be

Address reprint requests to Dr. Jesaitis, Department of Chemistry, Montana State University, Bozeman, MT 59717.

Received for publication 14 August 1989 and in revised form 7 November 1989.

J. Clin. Invest.

(C) The American Society for Clinical Investigation, Inc. $0021-9738 / 90 / 03 / 0821 / 15 \quad \$ 2.00$

Volume 85, March 1990, 821-835 absent in X-linked and autosomal forms of chronic granulomatous disease $(5,6,9,10)$. Although one report suggests that the 22-kD subunit bears the heme and is the functional cytochrome $b(11)$, analysis of amino acid composition (8) does not support these conclusions. Indeed, quantitative analysis of the pure protein suggests that there may be more than one heme (8).

Superoxide production is activated in the phagolysosome formed when granulocytes engulf and kill microbes $(1,12)$. We have estimated that uniform production of $\mathrm{O}_{2}^{-}$over the entire cell surface at a rate of $100 \mathrm{nmol} / \mathrm{min}$ per $10^{7}$ cells generates, at most, local micromolar concentrations of toxic oxygen metabolites (13). Injury to tissue or cells by $\mathrm{H}_{2} \mathrm{O}_{2}$ occurs at fractional millimolar concentrations, although in the presence of myeloperoxidase and halide micromolar concentrations are sufficient to kill bacteria $(14,15)$. Thus, higher local concentrations of $\mathrm{O}_{2}^{-}$or highly localized generation of the radical might be necessary to induce sufficient cellular damage to produce pathogenic effects or kill certain more resistant microbes.

Higher rates of production of superoxide anion are achieved when phagocytes are exposed to lipopolysaccharide and other agents, such as certain lymphokines $(16,17)$. These agents prime cells $(18,19)$, increasing surface expression of certain receptors and other proteins. Part of this increase probably results from an induction of an increase in transcription of these proteins, one of which is the cytochrome $b$ heavy chain (20). Another explanation of this phenomena is that these agents may mobilize or translocate intracellular pools of membrane proteins such as the cytochrome $b(21)$, receptors, and other plasma membrane proteins $(22-25)$ to the cell surface in preparation for the final activating event that would trigger superoxide production and other microbicidal activities.

To shed additional light on the translocation hypothesis and to explore the structural constraints of cytochrome distribution on superoxide production during a microbicidal response, it has become necessary to define precisely the loci of these intracellular pools and the respective translocation events. As originally emphasized by de Duve (26), subcellular fractionation analysis can provide only part of the information required to localize specific cellular components. Thus, we investigated the electron microscopic immunolocalization of the 91- and 22-kD subunits of the cytochrome using the novel technique of cryofixation/molecular distillation drying (27, 28 ), in combination with highly specific affinity-purified anticytochrome antibodies. We compared the subcellular morphological localization of cytochrome $b$ in purified unstimulated neutrophils with those actively engulfing killed Staphylococcus aureus. We discovered that both subunits of cytochrome $b$ are localized to lactoferrin-bearing specific granules in unstimulated neutrophils. A small amount of cy- 
tochrome $b$ is detectable in the plasma membrane, consistent with subcellular fractionation analysis. Upon phagocytosis of serum-opsonized bacteria, a translocation of the cytochrome occurs from the granules to the phagosomal membrane contacting the bacterial wall.

\section{Methods}

\section{Preparation of neutrophils}

Human neutrophils were prepared by the method of Boyum in FicollHypaque and resuspended in Hank's balanced salt solution without $\mathrm{Ca}^{2+} / \mathrm{Mg}^{2+}$. Alternatively, cells were prepared by the method of Henson and Oades (29) and resuspended in Dulbecco's PBS.

\section{Preparation of affinity-purified antibody}

Rabbit antisera and purified cytochrome $b$ were prepared as previously described by Parkos et al. (6). The 22-kD subunit was excised directly from an unfixed SDS-polyacrylamide slab gel or an electrophoretic nitrocellulose transfer (i.e., Western blot) prepared and run as previously described $(6,30)$. Approximately $10 \mu \mathrm{g}$ of light chain was eluted from the homogenized gel slice $(0.5 \times 2 / 0.1 \mathrm{~cm})$ by incubation with $1 \mathrm{ml} \mathrm{SDS-PAGE} \mathrm{running} \mathrm{buffer} \mathrm{at} \mathrm{room} \mathrm{temperature} \mathrm{for} 2 \mathrm{~h}$ with shaking. $99 \%$ of the $22-\mathrm{kD}$ polypeptide was recovered, based on the rerunning of the eluted material on another gel and quantitating the staining by densitometry. The purity of this material was previously checked by microsequence analysis and shown to have a single cytochrome $b$ light chain $\mathrm{NH}_{2}$-terminal amino acid sequence (8). The polypeptide was then concentrated 10 -fold on a centricon 10 microconcentrator and twice rediluted to the original volume in $10 \mathrm{mM}$ Hepes, $100 \mathrm{mM} \mathrm{KCl}, 10 \mathrm{mM} \mathrm{NaCl}, 1 \mathrm{mM}$ EDTA, $10 \mu \mathrm{g} / \mathrm{ml}$ chymostatin, and $0.2 \mathrm{mM}$ PMSF, pH 7.4, containing $1 \%$ octyl glucoside. This material was then rotated end over end overnight with $1 \mathrm{ml}$ of a $1: 1$ mixture of Affigel 10,15 (Bio-Rad Laboratories, Richmond, CA) previously washed three times, first with isopropanol and then with distilled water. The slurry was then pumped dry and washed with $75 \mathrm{mM}$ Tris, $\mathrm{pH} 8.6$, in saline. The column retained between 90 and $100 \%$ of the polypeptide. Using $2 \mathrm{ml}$ of Affigel coupled to $22-\mathrm{kD}$ polypeptide, 5 $\mathrm{ml}$ of R3179 rabbit serum was pumped through at a flow rate of $5 \mathrm{ml} / \mathrm{h}$ overnight at $4^{\circ} \mathrm{C}$. The column was washed at a flow rate of $25 \mathrm{ml} / \mathrm{h}$ with $300 \mathrm{mM} \mathrm{NaCl}, 50 \%$ glycerol, and $10 \mathrm{mM}$ Hepes, pH 7.4, until A280 was $<0.05$. The retained antibody was then eluted with $1-2 \mathrm{ml}$ $25 \mathrm{mM}$ glycine/ $\mathrm{HCl}, \mathrm{pH} 2.8$, in $50 \%$ glycerol and collected in defined volumes of enough $500 \mathrm{mM}$ Hepes buffer, $\mathrm{pH} 7.4$, to raise the $\mathrm{pH}$ to 7 .

Antibody was affinity purified from nitrocellulose by first incubating the excised nitrocellulose with $10 \%$ goat serum, $3 \%$ BSA, $500 \mathrm{mM}$ $\mathrm{NaCl}$, and $10 \mathrm{mM}$ Hepes, $\mathrm{pH} \mathrm{7.4,} \mathrm{for} 30 \mathrm{~min}$, followed by a brief rinse in PBS. The strip was then incubated overnight with antisera containing $0.2 \%$ Tween 20 at $4^{\circ} \mathrm{C}$ and gently agitated. The next day it was first washed with PBS containing 0.2 Tween 20, followed by PBS alone. The bound antibody was eluted by incubation for $7 \mathrm{~min}$ in $3 \mathrm{ml}$ of 50 $\mathrm{mM}$ glycine $/ \mathrm{HCl}, \mathrm{pH} 2.8$, which was then neutralized with $1 \mathrm{M}$ Tris base and diluted 1:1 with glycerol.

Antisera against the 91-kD heavy chain of the cytochrome $b$ was obtained by injecting rabbits with keyhole limpet hemocyanin derivatized with the peptide KQSISNSESGPRGC, spanning position 546-558 in the primary structure of the heavy chain and a $\mathrm{COOH}$-terminal cysteine as previously described (31). This antisera was affinity purified on a matrix of a $50 \%$ mixture of Affigel 10 and 15 onto which $20 \mathrm{mg}$ peptide was bound in $100 \mathrm{mM}$ Hepes buffer, pH 7.4. The antisera was immunopurified as described above.

Sodium azide was added to both antibody solutions to a final concentration of $0.02 \%$ to inhibit bacterial growth. The final concentrations of the antibodies were $\sim 40$ and $50 \mu \mathrm{g} / \mathrm{ml}$. Positive antibody activity was detectable by micro-ELISA assay or Western blot analysis to dilutions of $1: 5,000-1: 1,000$, respectively.

\section{Antibody assays}

Micro-ELISA assay for the cytochrome $b$ was performed as previously described for lactoferrin (32) on poly-L-lysine-coated Immulon $2 \mathrm{mi}$ crotiter plates that were preincubated overnight with $150 \mathrm{ng}$ cytochrome $b$ per well in $25 \mathrm{mM} \mathrm{NaCl}, 10 \mathrm{mM}$ Hepes, and $0.01 \%$ Triton $\mathrm{X}-100$. The incubation was followed by a PBS wash and blocked with $2 \%$ BSA in PBS. Antibody was diluted in PBS containing 2\% BSA.

\section{Localization by subcellular fractionation analysis}

Subcellular fractionation was performed on $1 \times 10^{9}$ cells isolated by the method of Henson and Oades (29), disrupted by $\mathrm{N}_{2}$-cavitation at a concentration of $10^{8}$ cells $/ \mathrm{ml}$, and fractionated on a single 34-ml sucrose gradient by isopycnic sedimentation as previously described (32). $20 \mu \mathrm{l}$ of each fraction was run on a 7-18\% SDS-polyacrylamide slab gel and electrophoretically transferred to nitrocellulose for Western blot analysis with a 1:1,000 dilution of the affinity-purified antibodies as described previously (6). Western blot analysis was also performed on both low-speed pellet and supernatant fractions. Protein was determined using a protein assay kit (Bio-Rad Laboratories) using BSA as a standard. Cytochrome $b$ reduced minus oxidized difference spectroscopy, and analyses to determine peak plasma membrane and specific granule marker activity (alkaline phosphatase and lactoferrin, respectively) were performed as described by Parkos et al. (32).

\section{Cryofixation and sample preparation}

Purified neutrophils, suspended in Hank's balanced salt solution without $\mathrm{Ca}^{2+} / \mathrm{Mg}^{2+}$ at $1-10 \times 10^{7} / \mathrm{ml}$, were divided into $200-\mu \mathrm{l}$ aliquots and pelleted briefly (3-5 s) in an Eppendorf centrifuge (Beckman Instruments, Inc., Palo Alto, CA). The supernate was aspirated and the dry pellet of cells was scooped from the tube bottom and thinly smeared onto a cryofixation holder. The cells were then cryofixed on a Cf-100 (LifeCell Corp., The Woodlands, TX) and stored under liquid nitrogen until dried.

Molecular distillation drying was performed as described (27). After drying was complete, specimens were exposed to vapor phase osmium or paraformaldehyde vapor in the dryer for $3 \mathrm{~h}$ at room temperature. After flushing, the excess osmium or paraformaldehyde was then pumped out and Spurr's resin or araldite resin was introduced into the drier to infiltrate the specimens under vacuum. The specimens were then removed and heated to $60^{\circ} \mathrm{C}$ to cure the resin.

Thin sections of embedded neutrophils were cut on a Reichert ultracut E microtome (C. Reichert Optische Werke, Ag., Vienna, Austria) at room temperature and mounted on uncoated grids before immunolocalization studies.

\section{Neutrophil phagocytosis assay}

Purified neutrophils were resuspended in fresh autologous serum at 2 $\times 10^{7} / \mathrm{ml}$. A clinical isolate of $S$. aureus, previously grown to log phase in trypticase soy broth, boiled for $10 \mathrm{~min}$, washed two times, and frozen, was thawed and resuspended in fresh autologous serum at 2 $\times 10^{9} / \mathrm{ml} .200-\mu \mathrm{l}$ aliquots of cells and staphylococci were mixed and tumbled at $37^{\circ} \mathrm{C}$ in triplicate. Before combining the cells and organisms, an aliquot of cells was pelleted and cryofixed as time 0 cells. After 5,10 , and $15 \mathrm{~min}$ of $37^{\circ} \mathrm{C}$ tumbling, the remaining aliquots of cells plus bacteria were pelleted and cryofixed. All were stored under liquid $\mathrm{N}_{2}$ until molecular distillation dried.

\section{Colloidal gold immunolocalization studies}

Cytochrome b 559 localization. Thin sections were either floated on $2 \%$ glutaraldehyde as they were cut on the microtome, or mounted on grids and floated on drops of buffer or buffer with $2 \%$ glutaraldehyde for 2-3 $\mathrm{min}$ at room temperature. No differences were observed between these methods. Grids were then washed and blocked using $10 \%$ BSA in $10 \%(\mathrm{vol} / \mathrm{vol})$ serum of the species of origin of the biotinylated secondary antibody. Blocking was done for $30 \mathrm{~min}$ at room temperature. After washing, sections were floated on drops of either 1:2 anti-22-kD antibody, 1:2 anti-91-kD antibody, or a 1:4 mixture of the anti-22-kD antibody plus anti-91-kD antibody at $4^{\circ} \mathrm{C}$ overnight. 
After incubation, the sections were washed three times, floated on drops of 1:100 biotinylated goat anti-rabbit IgG (Vector Laboratories, Inc., Burlingame, $\mathrm{CA}$ ) for $1 \mathrm{~h}$ at room temperature, washed three times, and then floated on 1:80-1:100 20-nm colloidal gold conjugated with streptavidin (Bethesda Research Laboratories, Bethesda, MD). After 30 min the sections were washed three times, stained with supersaturated uranyl acetate for $10 \mathrm{~min}$ at room temperature, and then examined on a CT12 STEM electron microscope (Philips Electronic Instruments, Inc., Mahwah, NJ).

Lactoferrin localization. Grid-mounted sections were floated on saturated sodium metaperiodate for $5 \mathrm{~min}$, washed three times, blocked as above, washed, and then floated on drops of 1:100 rabbit anti-human lactoferrin (Cooper Biomedical, Malvern, PA) overnight at $4^{\circ} \mathrm{C}$. After washing, all subsequent steps were as described above.

Double-labeling studies. Grid-mounted sections were stained to localize cytochrome $b$ on one side of the section as described above, but uranyl acetate counterstaining was deleted. The sections were then turned over and the unstained side of the section was labeled for either lactoferrin or cathepsin G, using $5 \mathrm{~nm}$ colloidal gold, followed by uranyl acetate staining of the double-labeled sections.

\section{Results}

Antibody specificity. The ultrastructural localization of human neutrophil cytochrome $b$ using colloidal gold depends on the utilization of a highly specific, high-affinity antibody. Previous application of a polyclonal, polyspecific IgG fraction of rabbit antisera raised against partially purified cytochrome $b$ indicated that the cytochrome $b$ light chain-specific fraction of the antisera was of sufficiently high affinity for such purposes. However, the polyspecific nature (see Fig. 6 of reference 6) of the antisera precluded its use for localization purposes. To isolate only the light chain-specific antibody fraction, the $22-\mathrm{kD}$ subunit of the purified protein was isolated by preparative SDS-PAGE, electrophoretically transferred to nitrocellulose, excised, and used as an affinity matrix to bind and elute light chain-specific antibodies. Alternatively, the light chain was eluted from the appropriate region of the gel and bound to


Figure 1. Specificity of affinity-purified rabbit (anti-human cytochrome $b$ light chain) antibody. Human neutrophils were disrupted by $\mathrm{N}_{2}$ cavitation as described by Parkos et al. (6). The low-speed pellet fraction was resuspended in a volume of cavitation buffer equal to that of the original cell suspension $\left(10^{8}\right.$ cell equivalents $\left./ \mathrm{ml}\right)$. The low-speed pellet (lanes 2, 4, 6, and 8) and low-speed supernatant fractions (lanes 1, 2, 5, and 7) suspensions were solubilized in SDSPAGE sample buffer as described in Methods. Lanes 1-4 are Coomassie blue staining patterns; lanes 5-8 are Western blots using affinity-purified anti-cytochrome $b$ light chain (22-kD) antibody. Lanes 1 and 5, 2 and 6, 3 and 7, and 4 and 8 had 10, 7.5, 20, and 15 $\mu \mathrm{g}$ protein, respectively.
Affigel to provide an immobilized matrix of pure cytochrome. After binding and eluting the antibody, its titer was determined by ELISA assay to dilutions of $>1: 100$ or $400 \mathrm{ng} / \mathrm{ml}$. The specificity of the antibody preparation is shown in Fig. 1, where only a single band of antibody binding could be detected in a Western blot of the low-speed fractions of whole neutrophil homogenates. The specificity of the anti-cytochrome $b$ heavy chain peptide $\left({ }^{446} \mathrm{KQSISNSESGPRGC)}\right.$ antibody has been characterized in a separate study (31).

Subcellular fractionation analysis. To show that the antibody was appropriate for immunolocalization purposes, it was first used to confirm the distribution of the cytochrome $b$ light chain in neutrophil subcellular fractions prepared in isopycnic sucrose density gradients. Fig. 2 shows that the distribution of the light chain in the fractions, as determined by Western blot analysis, parallels the cytochrome $b$ spectral distribution. The major peaks of both activities centered in the specific granule/ Golgi-enriched fractions. The minor peaks also cosedimented with the plasma membrane alkaline phosphatase activity. In both cases, $\sim 20-30 \%$ of the total activity was found in the plasma membrane-enriched fractions. This distribution of the heavy chain matched that of the light chain, but showed significant degradation in the azurophil granule-enriched fractions due to the abundance of proteases in these organelles (not shown).

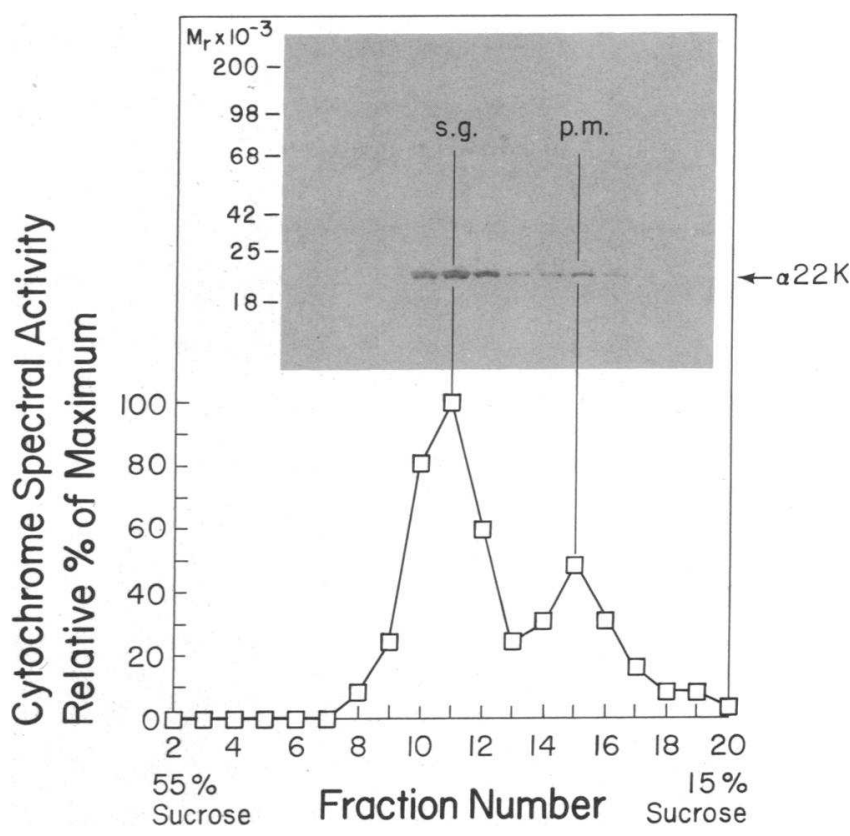

Figure 2. Subcellular distribution of cytochrome $b$ light chain and cytochrome $b$ spectrum in sucrose density gradients of human neutrophil homogenates. Sucrose density gradient fractions of $\mathrm{N}_{2}$ cavitation homogenates of human neutrophils, prepared as described in Methods, were analyzed for cytochrome $b$ content by reduced minus oxidized difference spectroscopy and by Western blot analysis using affinity-purified anti-cytochrome $b$ light chain antibody. The relative distribution of cytochrome $b$-specific Soret band absorbance and lanes of an SDS-PAGE/Western blot are aligned according to gradient fraction number. Molecular weight standard positions are shown to the left of the Western blot. Sucrose density increases as indicated from right to left. The supernatant fractions that had no cytochrome $b$ absorbance or staining are not shown. Peak position of the plasma membrane (p.m.) and specific granule (s.g.) marker activities are indicated. 




Figure 3. Immunocytochemical localization of cytochrome $b$ in purified human neutrophils. Cell sections were prepared from Spurr's resin blocks of osmicated and cryofixed, molecular distillation-dried cell preparations as described in Methods and labeled with affinity-purified anti-cytochrome $b$ light chain $(a-d)$ antibody. $a$ and $b$ display sections showing nearly whole cells. 20-nm grains are visible primarily on round or elliptical granules. Most of the label is observed within two- or three-grain diameters of the granule periphery. In some cases the labeling displays a rosetting pattern as shown in enlarged detail selected from other sections not prefixed with glutaraldehyde ( $c$ and $d$ ). Note plasma membrane labeling (arrowheads) and relatively sparse nuclear and extracellular labeling. The section shown in $a$ was exposed to $2 \%$ glutaraldehyde before antibody labeling. $e$ shows another whole cell incubated with normal rabbit IgG as a control. Infrequent grains are observed in the nucleus, cytoplasm, and extracellular space. Magnifications in $a-e$ are $\times 46,000, \times 33,800, \times 83,200, \times 83,200$, and $\times 49,300$, respectively. 

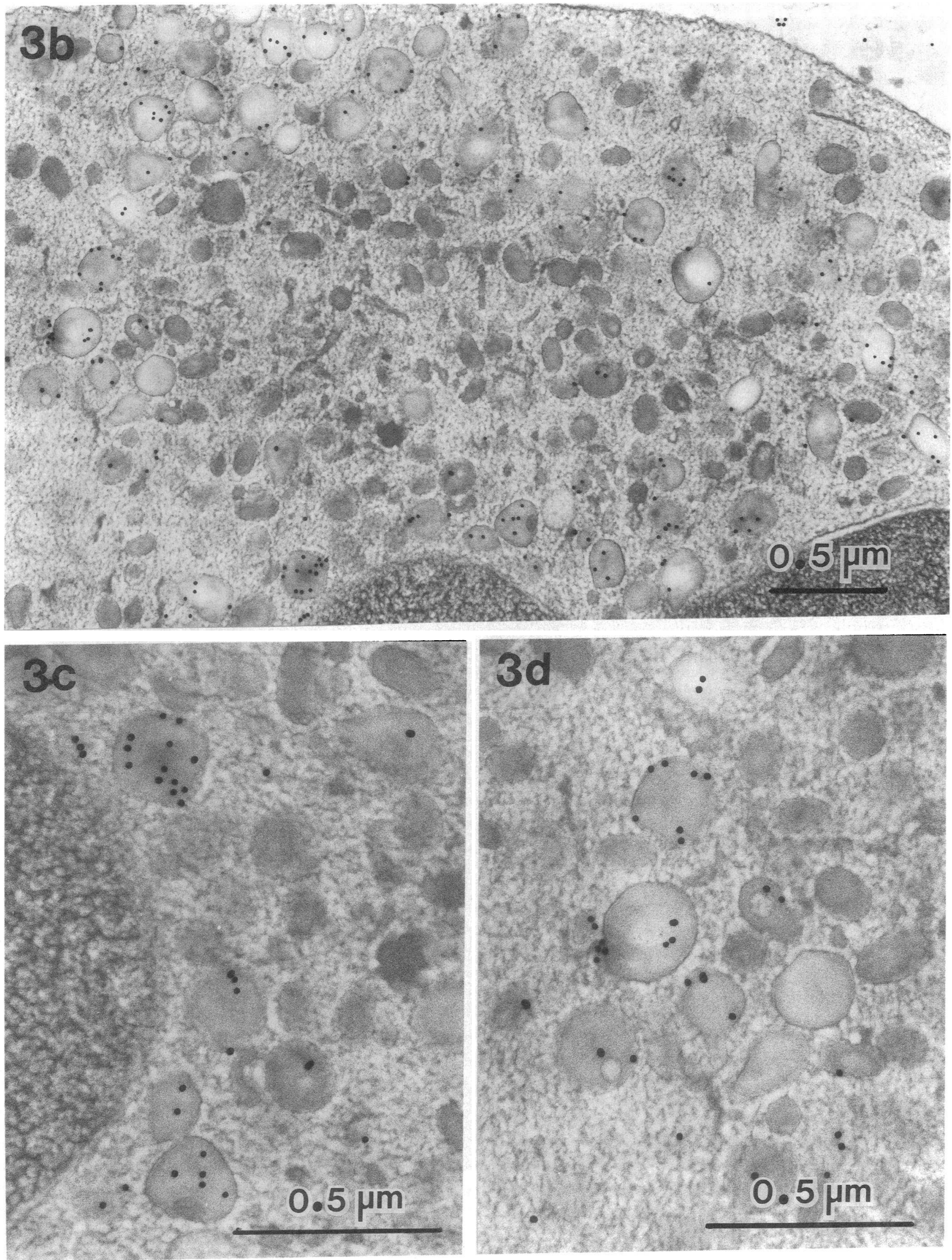

Figure 3 (Continued) 


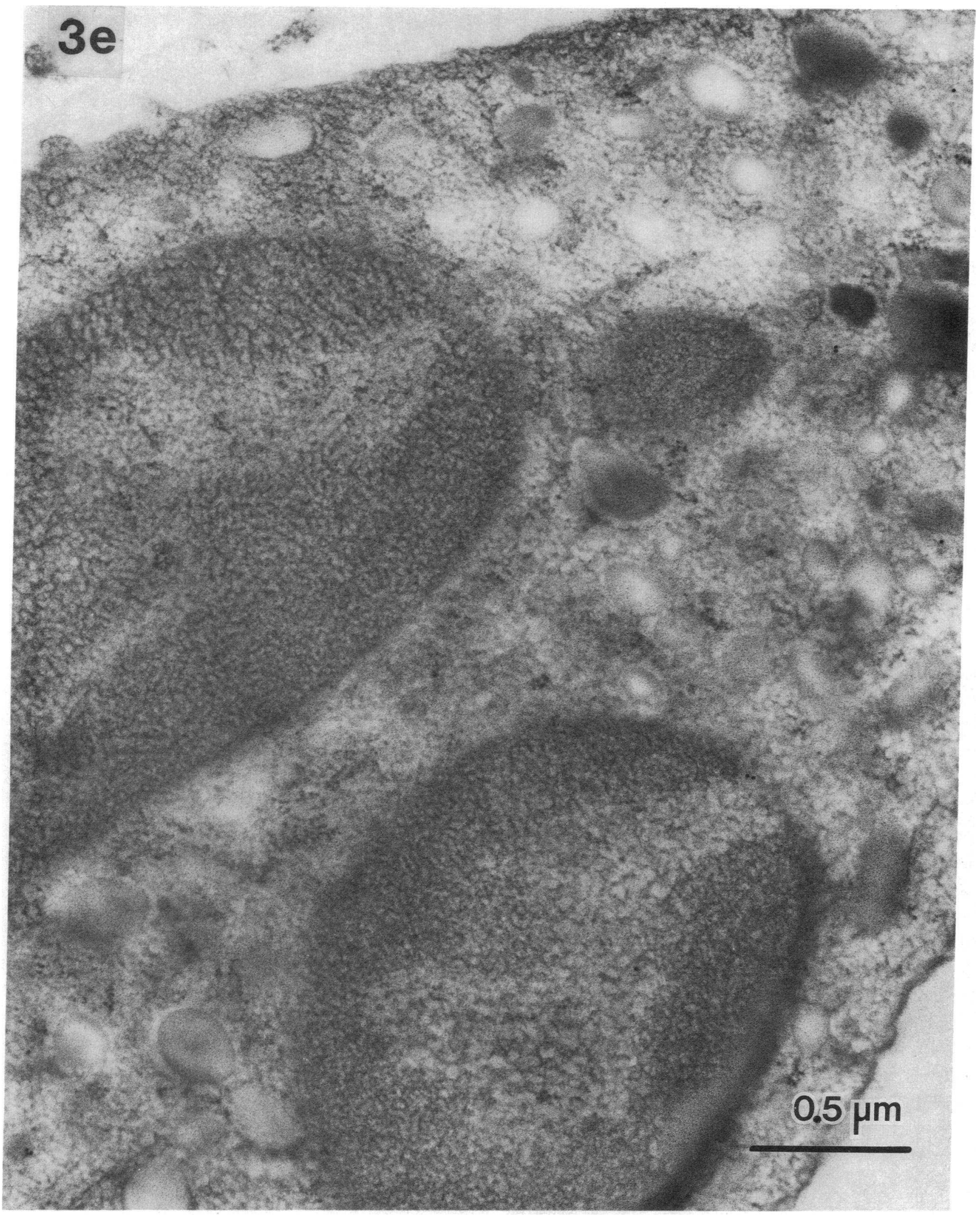

Figure 3 (Continued) 

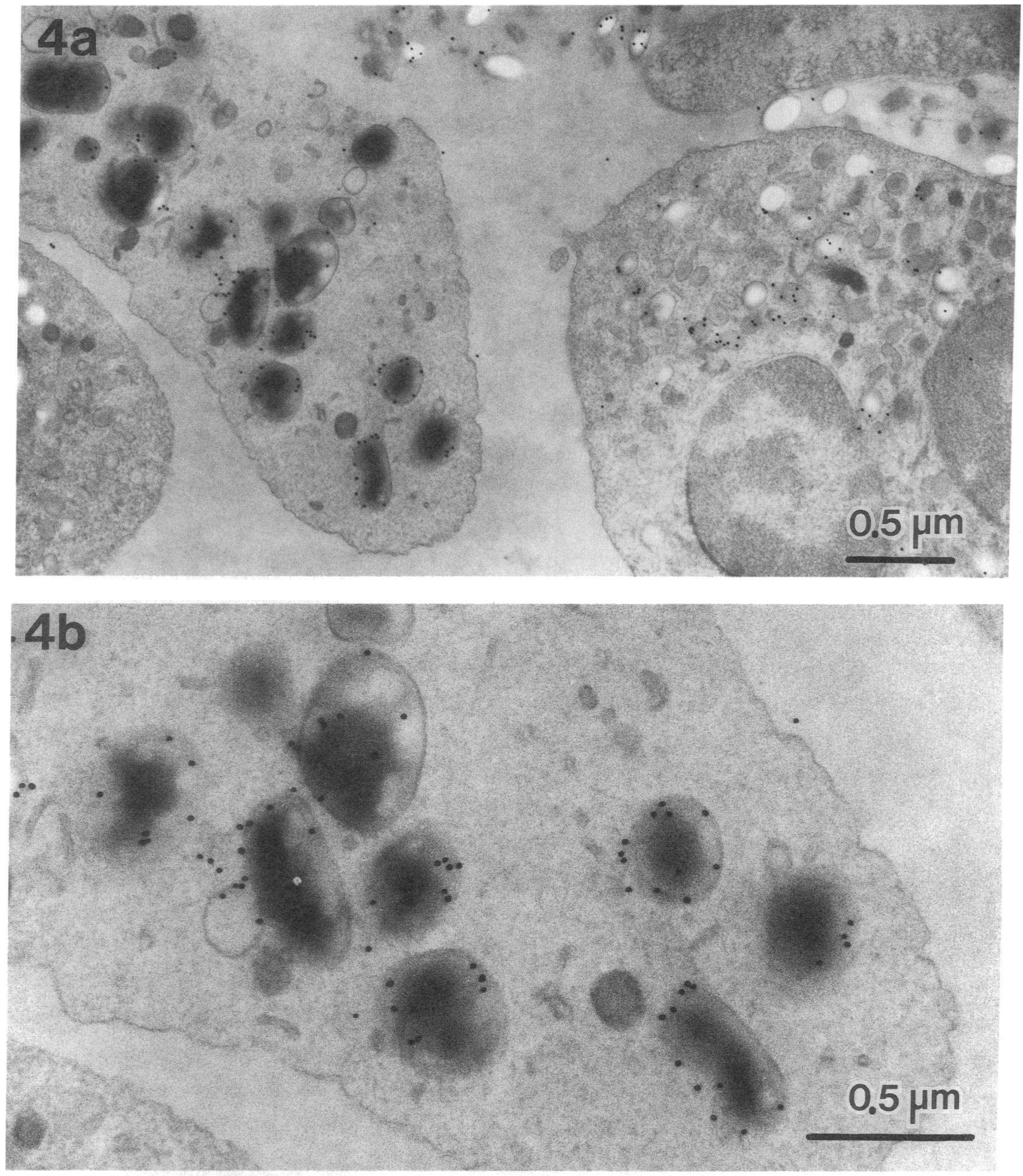

Figure 4. Immunocytochemical localization of cytochrome $b$ light chain in human eosinophils. Sections prepared as in Fig. 3, $b-d$ also contained eosinophils $(a)$, as evidenced by their large $(0.4-0.5 \mu \mathrm{m})$ secretory granules. Labeling in this instance was with 1:1 diluted antibody.

Granules clearly show cytochrome distributed along the organelle periphery as seen in the enlargement of the left cell of $a$, shown in $b$. Magnifcations in $a$ and $b$ are $\times 26,000$ and $\times 56,000$, respectively.

Localization in unstimulated neutrophils. To prove that a cell component is localized to a particular organelle, both a biochemical and morphological approach is necessary (26). Ultrastructural localization of the cytochrome would complement and confirm its biochemical localization. Cryofixation/ molecular distillation drying processing methodology for ultrastructural examination has the advantages of extremely rapid fixation, no organic solvent exposure, and no crosslinking prefixative use (28). Using this method, it was determined that the best labeling of antibody was observed at a 1:1 or no 


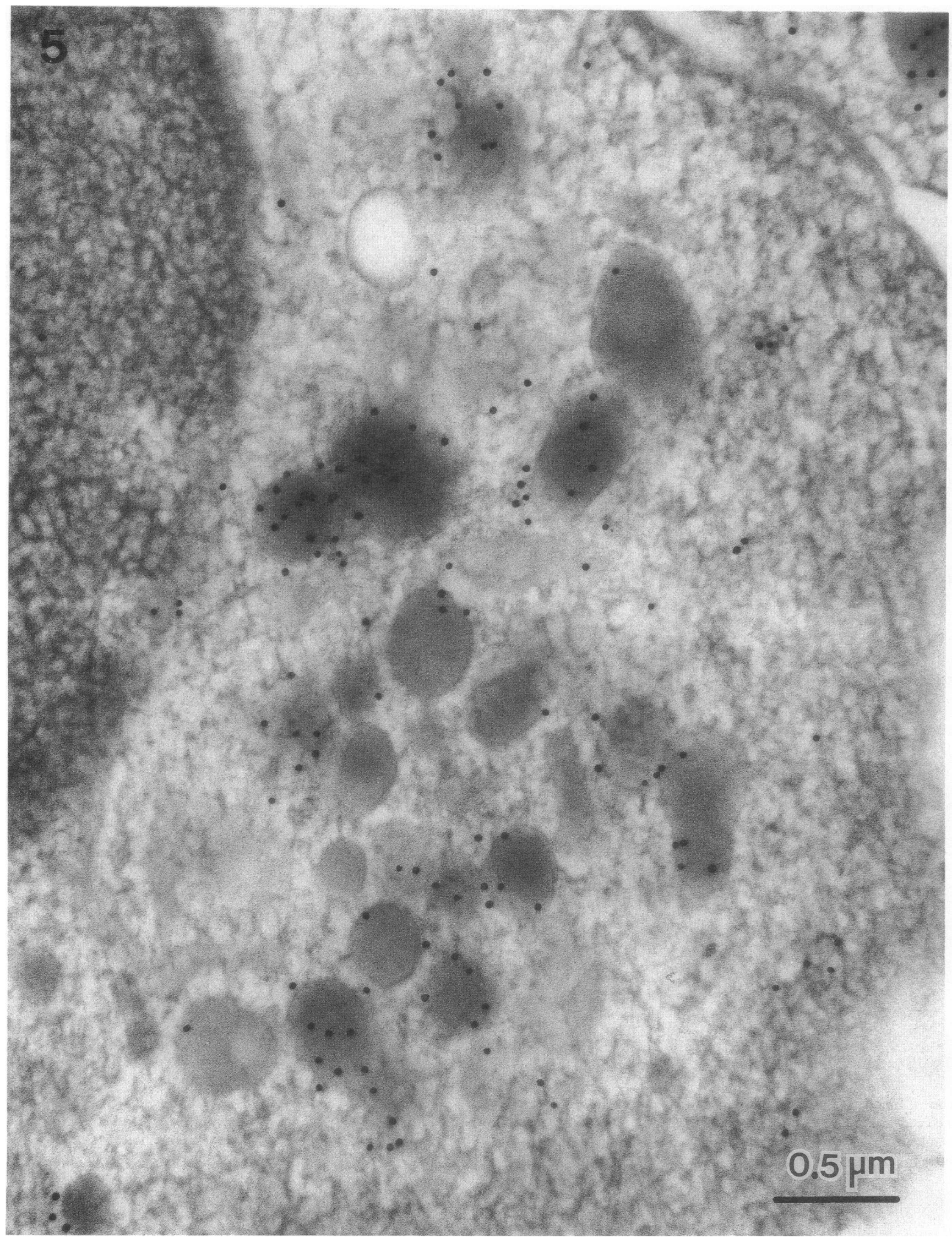

Figure 5. Localization of lactoferrin in specific granules of a human neutrophil. Cryofixed sections of human neutrophils labeled with rabbit anti-lactoferrin antibody show localization of lactoferrin using $10-\mathrm{nm}$ gold particles. Labeled structures have a similar appearance to those showing cytochrome localization in Fig. 3. Magnification is $\times 45,000$. 
dilution of the affinity-purified anti-cytochrome $b$ light chain antibody or anti-heavy chain peptide antibody in antibody dilution buffer. Fig. 3, $a-c$ shows the distribution of $20-\mathrm{nm}$ gold particles coupled to the cytochrome light chain by a biotin-conjugated goat anti-rabbit and gold-conjugated streptavidin sandwich. Most of the 1,591 grains counted (in 15 micrographs of 42 cells) were restricted to the interior $(19 \pm 5 \%)$ or periphery $(47 \pm 5 \%)$ of round or elliptical structures of uniform fine-grained density with maximum dimensions of $0.1-0.2$ $\mu \mathrm{m}$. Some grains were also observed along borders of similarly shaped structures, but empty of density, which probably represented granules whose contents had fallen out during sectioning. A small percentage $(6.3 \pm 1.5 \%)$ of grains were also within three diameters of the plasma membrane border. Some grains in the cytoplasm appeared not to be associated with any particular structure, possibly representing sections tangentially grazing a granule. Very little staining of the nucleus $(8 \pm 3 \%)$ or extracellular matrix was observed, indicating that the stain was highly specific. The distribution of grains within a cell were virtually identical when antibody directed against the heavy chain was used (not shown). Consistent with the low abundance of the antigen, the intensity but not the specificity of labeling was variable from cell to cell. IgG, prepared from normal rabbit serum at the dilution of the specific antibody and omission of primary antibody, resulted in sections virtually free of any staining (Fig. $3 e$ ).

Anti-cytochrome antibodies also labeled eosinophils in a specific fashion, as shown in Fig. 4. Distinct labeling was observed along the periphery of most of the larger $(0.4-0.5 \mu \mathrm{m})$ granules of this cell type. The larger size of these granules is necessary to observe membrane localization, and provides a measure of the resolution of this technique $(\sim 50 \mathrm{~nm})$. In the smaller neutrophil granule such a localization is not readily apparent, so distribution often does not appear to reflect such a membrane localization (Fig. $3 a$ ).

To identify the granule type bearing the cytochrome $b$ antibodies against lactoferrin were used. This protein is the major protein of specific granules. Fig. 5 shows this distribution of lactoferrin within a neutrophil. It is similar to that of cytochrome $b$, but does not show as many grains that are directly adjacent the boundary membrane. Smaller (10-nm) gold conjugates of streptavidin were used to detect lactoferrin on the opposite face of the section used to localize the cytochrome. In Fig. 6, $a-c$, it is evident that wherever grains of cytochromeassociated 20-nm particles are found, so are the smaller 10-nm particles, indicating the cytochrome $b$ is localized to the lactoferrin-bearing specific granules. Controls in which primary antibody was omitted showed virtually no staining (not shown). In preliminary studies cathepsin $G$, an azurophil granule protein, was shown to reside in granules similar in morphology to the lactoferrin-bearing granules, but never in the same granules that contained cytochrome labeling.

Localization in neutrophils engaged in phagocytosis. Since most of the cytochrome in resting cells seems to be localized to intracellular stores, neutrophils actively engaged in phagocytosis should display the localization of cytochrome $b$, characteristic of targeting of superoxide generation. It has previously been demonstrated ultrastructurally that $\mathrm{H}_{2} \mathrm{O}_{2}$, the ultimate product of the cytochrome $b$-containing oxidase, is produced at the phagosomal membrane after phagocytosis of zymosan (33). Consequently, neutrophils actively engaged in phagocytosis of bacteria ( $S$. aureus) were examined for cytochrome distribution. Fig. 7 shows that, in such cells, cytochrome $b$ appears to be inserted from intracellular stores into the membrane of phagolysosomes, gaining very close apposition to the particle surface. Of particular interest is the clustered appearance of cytochrome $b$ that is often observed in phagolysosomes labeled with the anti-light chain $(c)$ or anti-heavy chain antibodies $(d, e)$. When suspensions of bacteria alone were sectioned and analyzed by these methods, no cytochrome staining was observed (not shown), indicating that the staining derives from a neutrophil component and not artifactual staining of the bacterium.

\section{Discussion}

The purpose of this investigation was to determine the subcellular localization of human neutrophil cytochrome $b$ in resting and phagocytosing human neutrophils by electron microscopic methods. This determination would then permit confirmation of previous incomplete biochemical localizations, which relied solely on subcellular fractionation analysis, and provide further insight into the localization of the cytochrome in an activated functioning cell. Our results show that in resting neutrophils cytochrome $b$ resides primarily in an intracellular store of specific granule membranes that are translocated to the phagosomal membrane when neutrophils engage in phagocytosis.

The localization has relied on the affinity purification of two rabbit antisera. The first antisera, R3179, was previously used in the form of polyspecific whole serum (6) or IgG fraction. This use demonstrated, first, that the antisera recognized the cytochrome $b$ since it immunoprecipitated spectral activity; second, that it labeled a $22-\mathrm{kD}$ polypeptide in Western blots of extracts of normal human neutrophil, which was absent in Western blots of cytochrome negative extracts of neutrophils from patients with chronic granulomatous disease (6, 10 ); third, that it recognized only the $22-\mathrm{kD}$ subunit and not the $91-\mathrm{kD}$ subunit $(6,10)$; and finally, that it was successfully used to screen cDNA expression libraries for the cloning of the 22-kD light chain subunit (8). Affinity purification on matrices containing the purified light chain removed all other specificities $(6,10)$, as evidenced by the monospecific Western blot pattern observed in Fig. 1 and the immunopurification of cytochrome-containing protein complexes in octyl glucoside (31).

The second antisera bound the peptide ${ }^{446} \mathrm{KQSISN}$ SESGPRGC, which, except for the COOH-terminal amino acid residue, was derived from the sequence of the $91-\mathrm{kD}$ cytochrome subunit. This antisera was previously shown to specifically retain both subunits of the cytochrome on immunoaffinity matrices (31). Furthermore, it labels only the $91-\mathrm{kD}$ subunit in Western blots of neutrophil extracts.

Our application (Jesaitis, A., C. M. Chang, and M. Wilhite, unpublished observations) of these antibodies to frozen thin sections made of lightly fixed cells (34) proved to be inconclusive with respect to localization of the cytochrome $b$ antigens in neutrophils. Nonspecific staining was absent, as judged by the lack of labeling outside the cell periphery. In addition, staining could be inhibited by inclusion of free peptide antigen in the incubation mix. However, the staining in the section showed no defined localization. Instead, a more disperse labeling was evident, probably resulting from inadequate antigen immobilization or epitope preservation. This result led us to 


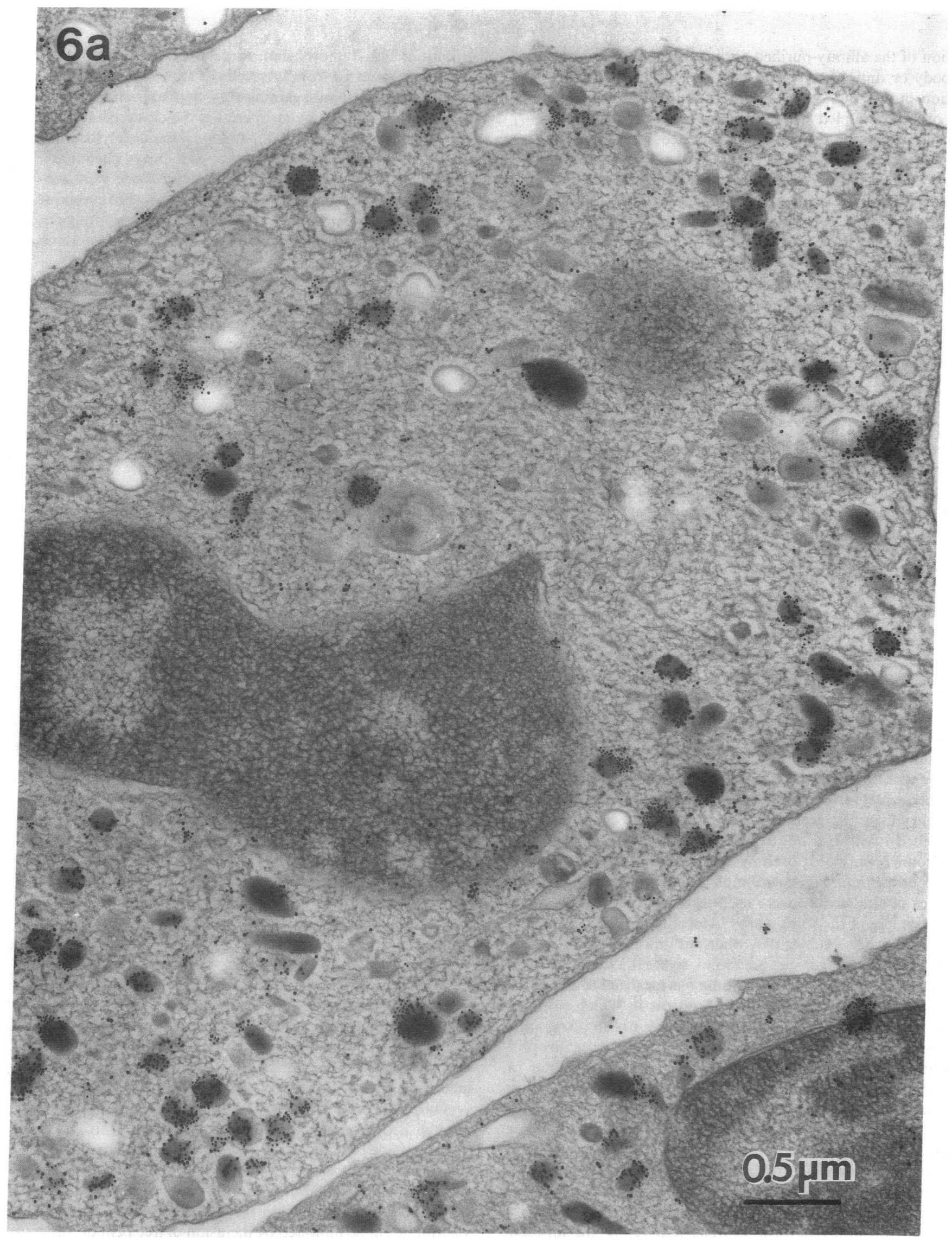

Figure 6. Colocalization of cytochrome $b$ and lactoferrin in specific granules of human neutrophils. Cryofixed sections of human neutrophils were double labeled on opposite sides of the section with rabbit anti-lactoferrin antibodies or a cocktail of rabbit anti-cytochrome $b$ light and heavy chain antibodies (mixed 1:1). The faces were developed with 10- and 20-nm gold conjugates, respectively. Common localization of the three antigens is observed in nearly every case throughout the cell shown in $a$, and enlarged regions shown in $b$ and $c$. Since lactoferrin is by definition a specific granule content protein, cytochrome $b$ must be localized to specific granules. Magnification is $\times 46,700$ in $a$ and $\times 99,000$ in $b$ and $c$. 

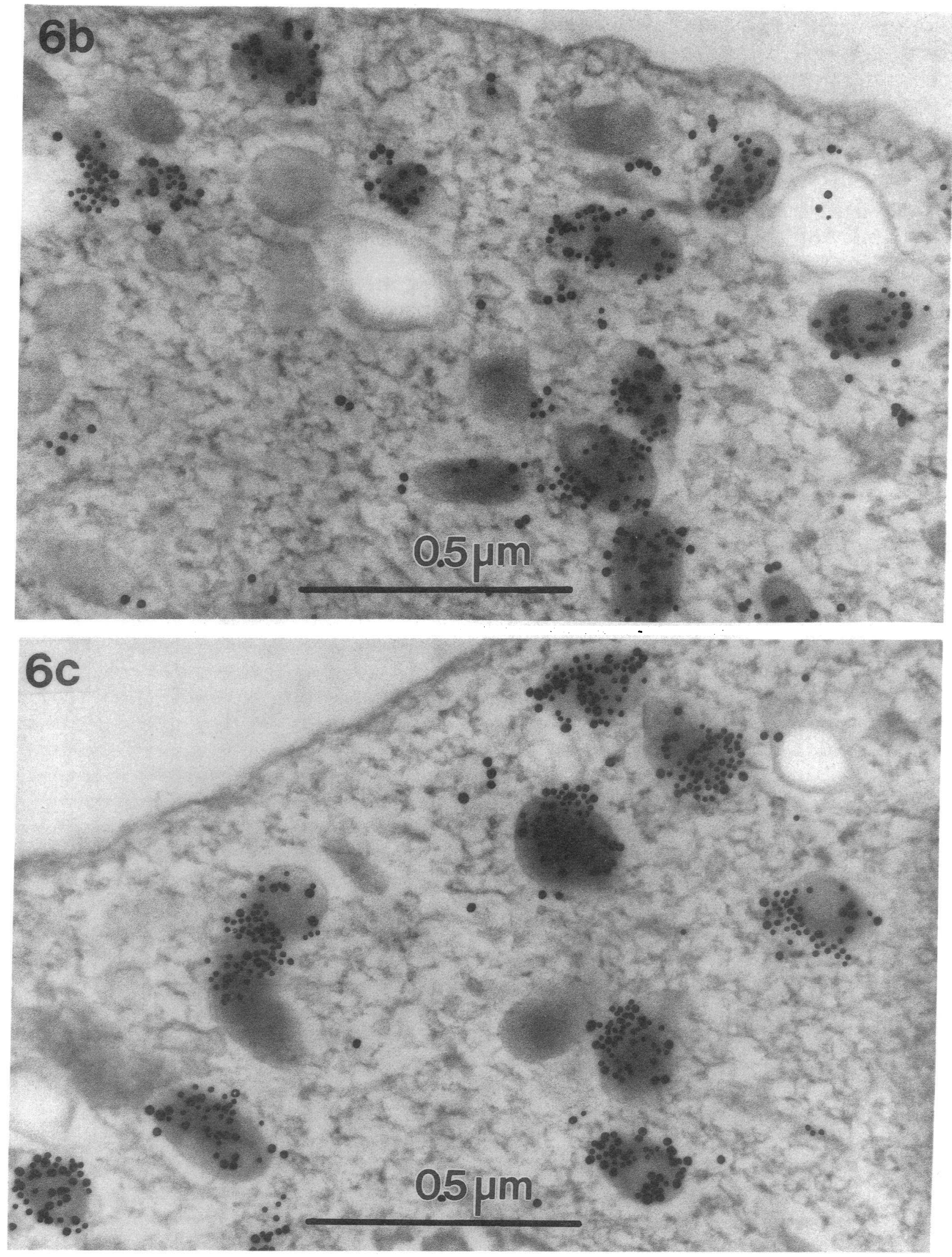

Figure 6 (Continued) 



Figure 7. Translocation of cytochrome $b$ from granules to the phagolysosomes during phagocytosis of killed $S$. aureus by human neutrophils. Human neutrophils were incubated with $S$. aureus for $15 \mathrm{~min}$ as described in Methods. Cryofixed sections of samples incubated with the bacteria were prepared and labeled with anti-cytochrome $b$ light chain $(c)$ or heavy chain ( $d$ and $e$ ) antibodies as described in Methods. Cytochrome $b$ was observed in the specific granules (arrows) and in the bacteria-containing phagolysosomes (arrowheads). Enlarged details of the bacteriacontaining phagolysosomes are shown in panels $c-e$. Magnification is $\times 32,000$ in $a$ and $b, \times 230,000$ in $c$, and $\times 198,000$ in $d$ and $e$. 

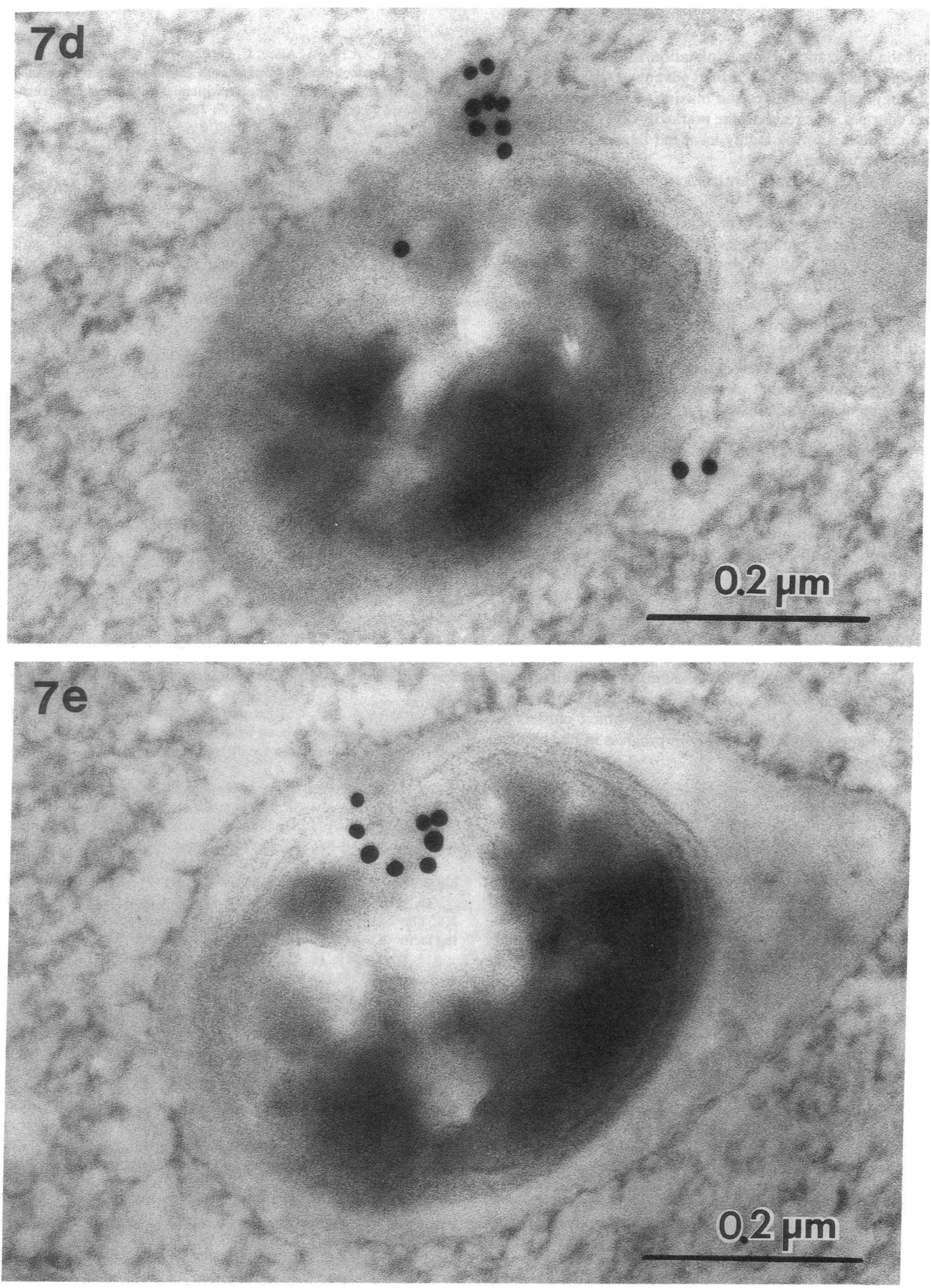

Figure 7 (Continued) 
attempt the localization using cryofixation/molecular distillation drying. This method has distinct advantages in preserving morphology without fixatives and maximizing preservation of antigen epitopes. The results were markedly different than the former method, showing highly localized labeling of distinct identifiable structures.

The localization of cytochrome $b$ to the specific granules rules out the possibility that it is localized to another fraction of the cell with similar sedimentation properties to the lactoferrin-bearing specific granules. Candidates for such fractions included Golgi (22), tertiary granules $(25,35,36)$, and phosphasomes (37). One alternate possibility remaining, consistent with our observations, is the existence of very small vesicles involved in intracellular transport of the cytochrome to and from the plasma membrane, Golgi, and lysosomes. As can be seen in Figs. 3, 6, and 7, some grains appear in the cytoplasm that are apparently unassociated with easily visible granules. Such labeling would be consistent with very small structures or tangential sections of granules.

Translocation of neutrophil cytochrome $b$ to the phagosomal membrane of phagocytosing neutrophils has been previously demonstrated (38) using subcellular fractionation analysis. Our results morphologically confirm this localization. The localization often appeared as clusters in the phagosome, which, if not artifactual, would reflect a nonuniform distribution. It is of interest that in phorbal myristate acetatestimulated cells all superoxide-generating activity appears to be localized on the cytoskeleton (39), cytoskeleton-enriched membrane domains (40), or detergent stable particles containing flavin, cytochrome $b$, and cytoskeletal protein, suggesting direct or indirect anchorage $(39,40)$ to the cell cytoskeleton. At this juncture we can only speculate as to whether there is any functional relevance to the observed cytochrome $b$ clusters in phagolysosomes. Work is currently in progress in our laboratory to address this question.

\section{Acknowledgments}

These studies were supported by United States Public Health Service (USPHS) grants RO1 AI-26711, PO1 HD-13021-09 (to Dr. Buescher), and Meadows Foundation grant 86010055 (to Dr. Linner and Dr. Livesey). Dr. Jesaitis is the recipient of an American Heart Association Established Investigator Award and Grant-in-AID with funds contributed in part by the California Affiliate. Dr. Quinn was supported by USPHS postdoctoral training grant HL-07195-12 at the Scripps Clinic and Research Foundation.

\section{References}

1. Borregaard, N. 1988. The respiratory burst: an overview. In The Respiratory Burst and Its Physiological Significance. A. J. Sbarra and R. R. Strauss, editors. Plenum Publishing Corp., New York. 1-31.

2. Babior, B. M. 1988. The respiratory burst oxidase. In Phagocytic Defects II. J. T. Curnutte, editor. W. B. Saunders Company, Philadelphia. 201-212.

3. Curnutte, J. T., and B. M. Babior. 1987. Chronic granulomatous disease. In Advances in Human Genetics. H. Harris and K. Hirschorn, editors. Plenum Publishing Corp., New York. 229-297.

4. Curnutte, J. T. 1988. Phagocytic defects II: abnormalities in the respiratory burst. In Hematology/Oncology Clinics of North America. W. B. Saunders Company, Philadelphia. 185-336.

5. Segal, A. W. 1987. Absence of both cytochrome b-245 subunits from neutrophils in X-linked chronic granulomatous disease. Nature (Lond.). 326:88-91.
6. Parkos, C. A., R. A. Allen, C. G. Cochrane, and A. J. Jesaitis. 1987. Purified cytochrome $b$ from human granulocyte plasma membrane is comprised of two polypeptides with relative molecular weights of 91,000 and 22,000. J. Clin. Invest. 80:732-742.

6a. Parkos, C. A., R. A. Allen, C. G. Cochrane, and A. J. Jesaitis. 1988. The quaternary structure of the plasma membrane b-type cytochrome of human granulocytes. Biochim. Biophys. Acta. 932:71-83.

7. Royer-Pokora, B., L. M. Kunkel, A. P. Monaco, S. C. Goff, P. E. Newburger, R. L. Baehner, F. S. Cole, J. T. Curnutte, and S. H. Orkin. 1986. Cloning the gene for an inherited human disorder-chronic granulomatous disease-on the basis of its chromosomal location. $\mathrm{Na}$ ture (Lond.). 322:32-38.

8. Parkos, C. A., M. C. Dinauer, L. E. Walker, R. A. Allen, A. J. Jesaitis, and S. H. Orkin. 1988. The primary structure and unique expression of the $22 \mathrm{kd}$ light chain of human neutrophil cytochrome $b$. Proc. Natl. Acad. Sci. USA. 85:3319-3323.

8a. Teahan, C., P. Rowe, P. Parker, N. Totty, and A. W. Segal. 1987. The $\mathrm{x}$-linked chronic granulomatous disease gene codes for the $\beta$-chain of cytochrome $b_{-245}$. Nature (Lond.). 327:720-721.

9. Dinauer, M. C., S. H. Orkin, R. Brown, A. J. Jesaitis, and C. A. Parkos. 1987. The glycoprotein encoded by the X-linked chronic granulomatous disease locus is a component of the neutrophil cytochrome b complex. Nature (Lond.). 327:717-720.

10. Parkos, C. A., M. Dinauer, A. J.. Jesaitis, S. Orkin, and J. T. Curnutte. 1989. Absence of both the $91 \mathrm{~K}$ and $22 \mathrm{~K}$ subunits of cytochrome b-559 in two genetic forms of chronic granulomatous disease. Blood. 73:1416-1420.

11. Yamaguchi, T., T. Hayakawa, M. Kaneda, K. Kakinuma, and A. Yoshikawa. 1989. Purification and some properties of the small subunit of cytochrome b558 from human neutrophils. J. Biol. Chem. 264:112-118.

12. Briggs, R. T., D. B. Drath, and M. L. Karnovsky. 1975. Localization of NADH oxidase on the surface of human polymorphonuclear leukocytes by a new cytochemical method. J. Cell Biol. 67:566586.

13. Jesaitis, A. J., R. A. Allen, and C. A. Parkos. 1988. Activation of the neutrophil respiratory burst by chemoattractants: regulation of the $\mathrm{N}$-formyl peptide receptor in the plasma membrane. J. Bioenerg. Biomembr. 20:679-707.

14. Schraufstatter, I. V., P. A. Hyslop, J. J. Jackson, S. D. Revak, and C. G. Cochrane. 1988. Biochemical mechanisms of oxidant and protease lung injury. In Human Inflammatory Disease: Clinical Immunology. Vol. 1. B. C. Decker Inc., Philadelphia. 59-67.

15. Klebanoff, S. J. 1968. Myeloperoxidase-halide-hydrogen peroxide antibacterial system. J. Bacteriol. 95:2131-2138.

16. Weisbart, R. H., D. W. Golde, S. C. Clark, G. G. Wong, and J. C. Gasson. 1985. Human granulocyte-macrophage colony-stimulating factor is a neutrophil activator. Nature (Lond.). 314:361-363.

17. Weisbart, R. H., D. W. Golde, and J. C. Gasson. 1986. Biosynthetic human GM-CSF modulates the number and affinity of neutrophil f-Met-Leu-Phe receptors. J. Immunol. 137:3584-3587.

18. Guthrie, L. A., L. C. McPhail, P. M. Henson, and R. B. Johnston, Jr. 1984. Priming of neutrophils for enhanced release of oxygen metabolites by bacterial lipopolysaccharide. J. Exp. Med. 160:16561671.

19. Lopez, A. F., J. Williamson, J. R. Gamble, C. G. Begley, J. Harlan, S. J. Klebanoff, A. Waltersdorph, G. Wong, S. C. Clark, and M. A. Vadas. 1986. Recombinant human granulocyte-macrophage colony-stimulating factor stimulates in vitro mature human neutrophil and eosinophil function, surface receptor expression, and survival. $J$. Clin. Invest. 78:1220-1228.

20. Nathan, C. F., and S. Tsunawaki. 1986. Secretion of toxic oxygen products by macrophages: regulatory cytokines and their effects on the oxidase. Ciba Found. Symp. 118:211-230.

21. Borregaard, N., J. M. Heiple, E. R. Simons, and R. A. Clark. 1983. Subcellular localization of the b-cytochrome component of the human neutrophil microbicidal oxidase. Translocation during activation. J. Cell Biol. 97:52-61. 
22. Jesaitis, A. J., J. R. Naemura, R. G. Painter, L. A. Sklar, and C. G. Cochrane. 1982. Intracellular localization of $\mathrm{N}$-formyl chemotactic receptor and $\mathrm{Mg}++$ dependent ATPase in human granulocytes. Biochim. Biophys. Acta. 719:556-568.

23. Fletcher, M. P., and J. I. Gallin. 1983. Human neutrophils contain an intracellular pool of putative receptors for the chemoattractant N-formyl-methionyl-leucyl-phenylalanine. Blood. 62:792799.

24. Fletcher, M. P., and J. I. Gallin. 1980. Degranulation stimuli increase the availability of receptors in human neutrophils for the chemoattractant f-Met-Leu-Phe. J. Immunol. 124:1585-1588.

25. Borregaard, N., L. J. Miller, and T. A. Springer. 1987. Chemoattractant-regulated mobilization of a novel intracellular compartment in human neutrophils. Science (Wash. DC). 237:1204-1205.

26. de Duve, C. 1971. Tissue fractionation. Past and present. J. Cell Biol. 50:20D-55D.

27. Linner, J. G., S. A. Livesey, D. S. Harrison, and A. L. Steiner. 1986. A new technique for removal of amorphous phase tissue water without ice crystal damage: a preparative method for ultrastructural analysis and immunoelectron microscopy. J. Histochem. Cytochem. 34:1123-1135.

28. Livesey, S. A., and J. G. Linner. 1987. Cryofixation taking on a new look. Nature (Lond.). 327:255-256.

29. Henson, P. M., and Z. G. Oades. 1975. Stimulation of human neutrophils by soluble and insoluble immunoglobulin aggregates. $J$. Clin. Invest. 56:1053-1061.

30. Towbin, H., T. Staehelin, and J. Gordon. 1979. Electrophoretic transfer of proteins from polyacrylamide gels to nitrocellulose sheets: procedure and some applications. Proc. Natl. Acad. Sci. USA. 76:4350-4354.

31. Quinn, M. T., C. A. Parkos, L. Walker, S. H. Orkin, M. C. Dinauer, and A. J. Jesaitis. 1989. Association of a Ras-related protein with cytochrome b of human neutrophils. Nature (Lond.). 342:198200.
32. Parkos, C. A., C. G. Cochrane, M. Schmitt, and A. J. Jesaitis. 1985. Regulation of the oxidative response of human granulocytes to chemoattractants: no evidence for stimulated traffic of redox enzymes between endo and plasma membranes. J. Biol. Chem. 260:6541-6547.

33. Ohno, Y.-I., K.-I. Hirai, T. Kanoh, H. Uchino, and K. Ogawa. 1982. Subcellular localization of hydrogen peroxide production in human polymorphonuclear leukocytes stimulated with lectins, phorbol myristate acetate, and digitonin. An electron microscopic study using $\mathrm{CeCl}_{3}$. Blood. 60:1195-1202.

34. Tokuyasu, K. T., and S. J. Singer. 1976. Improved procedures for immunoferritin labeling of ultrathin frozen sections. J. Cell Biol. 71:894-906.

35. Dewald, B., U. Bretz, and M. Baggiolini. 1982. Release of gelatinase from a novel secretory compartment of human neutrophils. J. Clin. Invest. 70:518-525.

36. Mollinedo, F., and D. L. Schneider. 1984. Localization of cytochrome $b$ and ubiquinone in a tertiary granule of resting human neutrophils and evidence for a proton pump ATPase. J. Biol. Chem. 259:7143-7150.

37. Smith, G. P., G. Sharp, and T. J. Peters. 1985. Isolation and characterization of alkaline phosphatase-containing granules (phosphasoines) from human leucocytes. J. Cell Sci. 76:167-178.

38. Segal, A. W., and O. T. G. Jones. 1978. Novel cytochrome b system in phagocytic vacuoles of human granulocytes. Nature (Lond.). 276:515-517.

39. Babior, B. M., J. T. Curnutte, and N. Okamura. 1988. The respiratory burst oxidase and certain members of the $48 \mathrm{~K}$ phosphoprotein family are associated with the neutrophil cytoskeleton. Blood. 72:141a. (Abstr.)

40. Quinn, M. T., C. A. Parkos, and A. J. Jesaitis. 1989. The lateral organization of components of the membrane skeleton and superoxide generation in the plasma membrane of stimulated human neutrophils. Biochim. Biophys. Acta. 987:83-94. 